\title{
Food insecurity measurement and prevalence estimates during the COVID-19 pandemic in a repeated cross-sectional survey in Mexico
}

\author{
Pablo Gaitán-Rossi ${ }^{1} \odot$, Mireya Vilar-Compte ${ }^{1, *} \odot$, Graciela Teruel $^{1}$ and \\ Rafael Pérez-Escamilla ${ }^{2}$ \\ 'Research Institute for Equitable Development EQUIDE, Universidad Iberoamericana, Prolongación Paseo de la \\ Reforma 880, Lomas de Santa Fé, Mexico City 01219, Mexico: ${ }^{2}$ Department of Social and Behavioral Sciences, \\ Yale School of Public Health, New Haven, CT, USA
}

Submitted 31 July 2020: Final revision received 5 0ctober 2020: Accepted 8 0ctober 2020: First published online 14 0ctober 2020

\begin{abstract}
Objective: To validate the telephone modality of the Latin American and Caribbean Food Security Scale (ELCSA) included in three waves of a phone survey to estimate the monthly household food insecurity prevalence during the COVID-19 pandemic in Mexico.

Design: We examined the reliability and internal validity of the ELCSA scale in three repeated waves of cross-sectional surveys with Rasch models. We estimated the monthly prevalence of food insecurity in the general population and in households with and without children and compared them with a national 2018 survey. We tested concurrent validity by testing associations of food insecurity with socioeconomic status and anxiety.

Setting: ENCOVID-19 is a monthly telephone cross-sectional survey collecting information on the well-being of Mexican households during the pandemic lockdown. Surveys used probabilistic samples, and we used data from April ( $n$ 833), May ( $n$ 850) and June 2020 ( $n$ 1674).

Participants: Mexicans 18 years or older who had a mobile telephone.

Results: ELCSA had an adequate model fit and food insecurity was associated, within each wave, with more poverty and anxiety. The COVID-19 lockdown was associated with an important reduction in food security, decreasing stepwise from $38.9 \%$ in 2018 to $24.9 \%$ in June 2020 in households with children.

Conclusions: Telephone surveys were a feasible strategy to monitor reductions in food security during the COVID-19 lockdown.
\end{abstract}

Keywords:
COVID-19
ELCSA
Food security
Mexico
Validity
The number of people with severe food insecurity has been rising globally since 2014 and the COVID-19 pandemic will likely reduce food security even further ${ }^{(1)}$. Several socioeconomic and health pathways can contribute to such reduction. Even though the association between household income and food security is well established ${ }^{(2)}$, the COVID-19 pandemic constitutes an important external socio-economic shock to households because of its effects in unemployment, poverty and a subsequent reduction in food purchases ${ }^{(3)}$. In the USA, households that allocate a higher income share on food are affected the most by economic shocks ${ }^{(4)}$, and previous studies have found that severe economic crises, such as the one in 2008, reduced food security in Mexican households and had a larger effect among households with lower income ${ }^{(5)}$. The economic shock is affecting more strongly households that were already vulnerable prior to the pandemic. Results from the Understanding Coronavirus in America cohort, a longitudinal survey conducted in Southern California, show that $40.5 \%$ of those living in households earning <US\$75 000 annually and who were employed in February 2020 have lost their job during the COVID-19 pandemic. Amongst them, $31 \%$ reported food insecurity and $33 \%$ reported eating less due to financial constraints ${ }^{(6)}$. Likewise, an analysis of five repeated online surveys of the US Supplemental Nutritional Assistance Program recipients documented that household food insecurity and financial debt worsened significantly between April and June 2020, when compared 
with the corresponding period of time in $2018^{(7)}$. A similar trend has been observed in middle-income countries. An online cross-sectional survey conducted between 27 March and 1 June 2020, in two favelas in Sao Paulo, Brazil, showed that $47 \%$ of respondents experienced moderate or severe food insecurity; $89 \%$ of them reported uncertainty to access food, $64 \%$ eating less than they should, and $39 \%$ skipping a meal ${ }^{(8)}$.

The current pandemic crisis has been long-lasting, and it is also affecting the food security of households that were not poor prior to the pandemic due to debt, temporary or permanent job loss or catastrophic illness ${ }^{(8)}$. In Vermont, USA, a cross-sectional survey collected from 29 March to 12 April 2020 showed a $33 \%$ increase in household food insecurity, with $35.6 \%$ of food insecure households classified as newly food insecure due to the pandemic and job loss being a main predictor of food insecurity ${ }^{(9)}$. An interrupted time series with a probabilistic sample in Bangladesh found sharp reductions in income, food security and mental health. During the lockdown, moderate food insecurity increased from 5.6 to $36.5 \%$ and severe food insecurity did so from 2.7 to $15.3 \%^{(10)}$.

In addition to its negative economic impacts, the needed social distancing measures are disrupting food systems leading to increased food prices and making it more difficult to access healthy foods ${ }^{(11)}$. A cross-sectional study conducted in the USA and China found shifting food consumption patterns during the lockdown, mostly caused by reduced options at supermarkets, and increases in household food insecurity ${ }^{(12)}$. Moreover, these measures may hinder the access to food assistance programmes, such as school meals ${ }^{(13)}$. Thus, a serious concern is that food consumption patterns during the pandemic can have negative health consequences following a syndemic pattern, including obesity and related diseases, as a result of increased consumption of ultra-processed foods, sugarsweetened beverages, sedentarism and reduced access to health services ${ }^{(3)}$.

Another consequence of experiencing food insecurity is poor mental health. A global analysis of the effects of food insecurity on mental health status found a consistent doseresponse; increasing food insecurity amplified diverse psychosocial stressors that were linked to heightened anxiety ${ }^{(14)}$. A recent meta-analysis identified that food insecurity has a significant effect on the likelihood of being stressed or depressed ${ }^{(15)}$. A US study conducted during the pandemic in a convenience sample found that households experiencing food insecurity were 2.09 and 1.88 times more likely to screen positive for anxiety and depression, respectively, than food secure households ${ }^{(16)}$. Food security in households with children requires particular attention ${ }^{(17)}$ because it has been associated with developmental risk and in low- and middle-income countries with lower vocabulary skills ${ }^{(18)}$. These child development delays can be mediated by depression or anxiety in caregivers $^{(19)}$. The economic crises and the social distancing measures have the potential to exacerbate the link between food insecurity and mental health ${ }^{(3)}$.

The disruption of the COVID-19 pandemic can amplify these adverse outcomes because the required attention may be insufficient in fragile health and mental health care systems in low- and middle-income countries ${ }^{(20)}$. The coexistence of COVID-19, food insecurity and anxiety, amidst poverty and unemployment, can be understood as a complex syndemic ${ }^{(3)}$. Syndemics are the aggregation of two or more health conditions driven by common factors which usually are disproportionately common in impoverished populations where health care is limited ${ }^{(21)}$. The long protracted nature of the COVID-19 pandemic will likely worsen this complex syndemic, increasing the severity of food insecurity ${ }^{(3)}$

Experienced-based food security scales - such as the Escala Latinoamericana y Caribeña de Seguridad Alimentaria (ELCSA) ${ }^{(22)}$ - have been shown to be costeffective and valid to assess food insecurity via face-to-face interviews in most countries in Latin America, Africa and Asia ${ }^{(23)}$. The COVID-19 pandemic made it impossible to conduct much needed food insecurity monitoring via face-to-face surveys in Mexico. Hence, a repeated, low-cost remote food insecurity assessment was warranted ${ }^{(24)}$. Telephone surveys were considered as a feasible strategy to address this need as interview mode (in-person $v$. telephone) has been shown before to have small effects on food security prevalence estimates; the adjusted OR of food insecurity comparing in-person with telephone interview in the USA was $1.036(P=0.088)^{(25)}$. Moreover, experienced-based food security scales had already been applied by telephone in middle- and high-income countries with at least $80 \%$ telephone coverage $^{(23)}$. To the extent of our knowledge, however, the assessment of food insecurity with an experiencedbased food security scale via nationally representative phone surveys during a public health emergency has not been properly validated.

The present study has three objectives. First, to compare the psychometric validity and reliability of ELCSA in a large face-to-face survey conducted prior to the pandemic and three waves of an adapted version collected through a telephone survey. Second, to assess the concurrent validity of the adapted ELCSA scale in the telephone survey. Lastly, to estimate the monthly prevalence of food insecurity in the general population and among households with and without children during the lockdown of the COVID-19 pandemic in Mexico.

As many other countries struck by the COVID-19, Mexico implemented a national lockdown measure from 17 March to 31 May. The Mexican government then shifted to a four-level risk system at the state level. However, during June 2020, most of the country remained at the 'red' level, indicating the highest risk, in which only essential businesses could operate and most of the households in the country had to maintain the lockdown. 


\section{Methods}

\section{Data source}

ENCOVID-19 is a monthly telephone cross-sectional survey, representative at a national level of individuals 18 years and older who have a mobile phone. This initiative is led by an academic research centre in strong partnership with international agencies and local civil society organisations. A key objective of ENCOVID-19 is to provide information to the media and decision-makers on the well-being of Mexican households during the COVID-19 pandemic. ENCOVID-19 is publicly available and offers timely data to decision-makers and the public at large on the social consequences of the lockdown measures in four main domains: labour, income, mental health and food security. It started in April 2020 and will continue for 12 more months ${ }^{(26)}$. The first ENCOVID-19 survey was collected from 6 April to 14 April ( $n$ 833), the second wave between 20 May and 25 May $(n 850)$ and the third wave between 5 June and 17 June ( $n$ 1674).

The monthly surveys were collected based on a onestage probabilistic sample of mobile telephone numbers which are randomly selected from the publicly available National Dialing Plan ${ }^{(27)}$. The number selection uses a single stratified random sampling for the thirty-two Mexican states and is implemented with Random Digit Dialing. As of 3 April 2020, the coverage of mobile phones in Mexico was $96 \%{ }^{(27)}$. Previous surveys from the National Institute of Statistics (INEGI for its acronym in Spanish) confirm the wide coverage of mobile phones in Mexico; in 2019, a national survey on the availability and use of technology found the coverage to be $89.4 \%$, but drops to $74 \%$ in rural areas ${ }^{(28)}$. Since the ENCOVID-19 might not reach isolated communities, post-stratification sampling weights were used to correct for minor deviations from the Mexican population's demographic structure. Weights were calculated using the 2015 census data from INEGI and adjust the sample by geographic distribution (state) and by sex, age and socio-economic status (SES). Further details of ENCOVID-19 and the composition of the sample are available elsewhere ${ }^{(26)}$.

The monthly surveys were collected by trained interviewers. In addition, a supervisor randomly assessed the quality of interviews through a quality control data management system. On average, the survey was collected in 18 min using Computer-Assisted Telephone Interviewing software. On June, the largest survey, a total of 53852 phone calls were effectively dialed, but 2400 numbers were inactive and 34080 calls sent automatically to voicemail. This volume of invalid numbers is expected in Random Digit Dialing surveys. In 17374 calls, a conversation ensued, $87 \%$ rejected the interview, $1.2 \%$ were ineligible (i.e. minors), $2 \%$ did not complete the interview and 9.6\% provided a full interview (a reasonable response in Random Digit Dialing surveys). Moreover, the quality assurance system required that all interviewers rate each interview at the end of the call: the majority (96-98\%) considered that the interviewees were interested in responding to the survey and between 94 and $97 \%$ believed that most of the responses to their questions were reliable. Importantly, they reported that they felt the interviewees understood the questions in the survey (94-95\%).

\section{Measures}

The study used three cross-sectional ENCOVID-19 waves (i.e. April, May and June). Household food insecurity was measured with the eight-item adult version of the ELCSA $^{(22)}$, which is the basis of the Food Insecurity Experience Scale ${ }^{(23)}$. ELCSA has been extensively validated for Mexico ${ }^{(29)}$ and is widely used in the country to measure multidimensional poverty ${ }^{(30)}$. It is also included in the Mexican National Health and Nutrition Survey (ENSANUT for its acronym in Spanish). Hence, the last ENSANUT conducted in 2018 was used to compare household food insecurity prevalence before the COVID-19 pandemic.

The ELCSA enquires if, in the last 3 months, due to a lack of money or other resources, the respondent or any other adult in the household: (i) worried you might run out of food (worried); (ii) were unable to eat healthy, balanced and nutritious food (healthy); (iii) ate only a few kinds of foods (fewfoods); (iv) skipped breakfast, lunch or dinner (skipped); (v) ate less than s/he thought should have (ateless); (vi) ran out of food (ranout); (vii) were hungry but did not eat (bungry) and (viii) went without eating for a whole day (whlday). Responses to all items are dichotomous (i.e. Yes/No). After computing the total summative score for the eight items, food (in)security was categorised into four levels: food security (total score $=0$ ), mild food insecurity (1-3), moderate food insecurity (4-6) and severe food insecurity (7-8). This method of estimation was followed in the current analysis; missing values for the food insecurity questions were minimal, with a maximum of $1.7 \%$ in April.

The usual way to use the ELCSA scale is by repeating, for each item, the 3-month time frame and emphasising lack of money or other resources as the cause to endorse the item. Since telephone surveys need to be short, an adapted version of the ELCSA was used in which the time and lack of resources framing was mentioned only once, before asking the items (see online supplementary material, Supplemental Materials S.1). Interviewers were instructed to repeat it whenever the respondent hesitated on the meaning of an item. The eight-item ELCSA was on average collected in 4 minutes.

Household SES was measured with the assets-based AMAI index ${ }^{(31)}$. It combines six household indicators from the National Income and Expenditure Survey ${ }^{(2)}$ : (i) education level of the head of household; (ii) number of complete bathrooms; (iv) number of cars or vans; (v) having Internet connection; (vi) number of household members 14 years or older who are working and (vii) number of bedrooms. Based on a summative score and standard cut-off points, SES is categorised into seven mutually exclusive categories, 
ranging from 'A/B' to ' $\mathrm{E}$ ', where $\mathrm{E}$ represents the lowest SES level.

Anxiety was measured with the two-item Generalised Anxiety Disorder scale ${ }^{(32)}$ that inquires about the frequency by which the respondent felt during the last 2 weeks: (i) nervous, anxious or on edge and (ii) not being able to stop or control worrying. Response options are 'never'; 'several days'; 'more than half of days' and 'almost every day'. An additive score of the responses was computed (range 0 to 6 ), and a cut-off point of 3 or more was used to classify as having anxiety disorder symptoms.

The surveys from May and June included a filter question to identify households with individuals under 18 years; this was unavailable for April. Hence, a dummy variable identifying households with children $(<18)$ or without children was generated to address differences in household food insecurity prevalence between these two types of families.

\section{Analysis}

Statistical analyses were conducted in four steps. First, general reliability estimates compared how consistently the ELCSA scale psychometrics performed in the different samples. Alpha and omega (with tethrachoric correlations) were estimated and compared; according to accepted standards ${ }^{(33)}$, values above 0.7 indicated adequate reliability and suggested high inter-item correlations.

Second, internal psychometric validity was assessed as recommended with the Rasch measurement model ${ }^{(34)}$. The Rasch model shows the extent to which observable items are consistent with the latent phenomenon, i.e. household food insecurity ${ }^{(35)}$. Estimations were conducted with the one-parameter logistic model using a conditional maximum likelihood approach and sampling weights at the household level from each survey ${ }^{(23)}$. Given the eight dichotomous responses to the ELCSA, the models yield item severity parameters indicating the location of the item on the latent variable. Higher severities correspond to items with higher levels of food insecurity and, therefore, with lower item means. Likewise, item severity was estimated for the total summative score as a way to assess if the items were measuring the whole range of the latent trait.

Item performance was assessed through infit statistics, which show the strength and consistency of the association between an item and the latent trait. The Rasch model assumes all items discriminate equally well and, if the assumption is met, infit statistics equal 1; nonetheless, infit values in the range $0 \cdot 7-1 \cdot 3$ are considered acceptable ${ }^{(23)}$. When the statistic is between 1.3 and 1.5 , items can still be used for measurement but should be closely monitored to establish if there is a systematic bias. Items with infit values above 1.5 should be discarded. Infit values below 0.7 are less worrisome because they indicate that the item's contribution may be redundant.

To assess the comparability of measures of fit between samples, a 'Flat' reliability test was performed. 'Flat' reliability measures the proportion of total variation in true severity accounted for by the model ${ }^{(23)}$. A good model fit has a reliability between 0.7 and 0.8 . Lastly, conditional independence of items was examined with an inspection of residual correlations, where it is expected they do not exceed 0.3 .

All the analyses were conducted for four surveys: ENSANUT 2018 and three cross-sections of the ENCOVID-19 (i.e. May to June). ENSAUT 2018 served as the pre-pandemic reference ( $n 44509$ ). Likewise, the analyses were conducted for households with and without children in the May to June samples.

The third step in the analysis focused in the concurrent validity assessed by correlating the ELCSA score with SES (Spearman correlation) and with anxiety (Welch twosample test). These analyses were conducted in a pooled dataset of the 3 months using the raw summative score of food insecurity (range 0-8). We hypothesised that food insecurity would have a negative association with SES, and higher levels of anxiety would be found in food insecure households.

In the fourth step, we estimated the prevalence of household food insecurity and assessed how much it changed over the first 3 months of the lockdown. Estimates from ENCOVID-19 were compared with those from ENSANUT 2018. The analysis was performed for the total sample and stratified by households with and without children.

All analyses were conducted in R software; Rasch models (RM) were ran using the RM.weights package, developed by FAO to conduct the statistical validation of the Food Insecurity Experience Scale ${ }^{(36)}$.

\section{Results}

The adapted version of the ELCSA scale used in ENCOVID19 repeated cross-sectional surveys was found to be reliable. The alpha coefficient for ENSANUT was 0.90, and the values for ENCOVID-19 - April, May and June ranged between 0.87 and 0.89 . A more stringent measure for dichotomous matrices showed similar results. While ENSANUT had an omega coefficient of 0.80 , the values of the ENCOVID were between 0.75 and 0.77 . Inter-item correlations were above the cut-off point of 0.6 in all surveys.

ELCSA's item severity parameters in the four surveys followed a similar order as the Food Insecurity Experience Scale global standard ${ }^{(23)}$ (Table 1). Severity parameters inversely mirror the mean's order and showed how the adapted version of the ELCSA in the ENCOVID-19 was able to measure the full range of the latent trait. ELCSA item's psychometric performance was adequate in the ENCOVID-19 surveys (Table 1). The only item with an infit statistic above the 1.3 threshold was 'ran out of food' (ranout), in May's wave, with a value of $1 \cdot 35$. This was not a concern since it represented 
Table 1 Comparison of weighted means and item severity parameters, infit and outfit statistics of the Latin American and Caribbean Food Security Scale (ELCSA) scale between the Mexican National Health and Nutrition Survey (ENSANUT) 2018 and the three ENCOVID-19 surveys from April, May and June 2020

\begin{tabular}{|c|c|c|c|c|c|c|c|c|c|c|}
\hline \multirow[b]{2}{*}{ Items } & \multicolumn{5}{|c|}{ ENSANUT 2018} & \multicolumn{5}{|c|}{ ENCOVID-19 April } \\
\hline & Means & Item sev. & SE & Infit & Outfit & Means & Item sev. & SE & Infit & Outfit \\
\hline Worried & $49 \cdot 3$ & $-3 \cdot 311$ & 0.022 & $1 \cdot 197$ & 2.907 & $52 \cdot 8$ & $-2 \cdot 717$ & 0.139 & 1.176 & 3.118 \\
\hline Fewfoods & 37 & $-1 \cdot 801$ & 0.019 & 0.846 & $1 \cdot 152$ & 36.4 & $-1 \cdot 16$ & 0.126 & 0.883 & 1.048 \\
\hline Healthy & 34.6 & -1.491 & 0.019 & 0.933 & 1.325 & 31.7 & -0.667 & 0.127 & 0.966 & 0.899 \\
\hline Ateless & 23.5 & -0.018 & 0.02 & 0.826 & 0.739 & 29.4 & -0.381 & 0.128 & 0.795 & 0.632 \\
\hline Ranout & 15 & 1.358 & 0.022 & 1.235 & 1.324 & 18 & 1.015 & 0.144 & 1.023 & 0.955 \\
\hline Skipped & 14.6 & 1.44 & 0.023 & 0.845 & 0.769 & $19 \cdot 2$ & 0.835 & 0.14 & 1.001 & 0.953 \\
\hline Hungry & $14 \cdot 1$ & 1.527 & 0.023 & 0.818 & 0.664 & $16 \cdot 7$ & $1 \cdot 198$ & 0.147 & 0.869 & 0.883 \\
\hline \multirow[t]{2}{*}{ Whlday } & $10 \cdot 7$ & $2 \cdot 296$ & 0.026 & 0.973 & 0.959 & $12 \cdot 3$ & 1.877 & 0.164 & 1.051 & 1.474 \\
\hline & \multicolumn{5}{|c|}{ ENCOVID-19 May } & \multicolumn{5}{|c|}{ ENCOVID-19 June } \\
\hline Items & Means & Item sev. & SE & Infit & Outfit & Means & Item sev. & SE & Infit & Outfit \\
\hline Worried & $58 \cdot 3$ & $-2 \cdot 613$ & 0.139 & $1 \cdot 154$ & 1.933 & $57 \cdot 7$ & $-2 \cdot 19$ & 0.087 & $1 \cdot 14$ & 1.375 \\
\hline Few foods & 31.2 & -0.285 & 0.124 & 0.922 & 0.861 & 38.5 & -0.644 & 0.08 & 1.062 & 1.278 \\
\hline Healthy & 34.4 & -0.607 & 0.122 & 1.062 & 1.3 & $37 \cdot 7$ & -0.589 & 0.08 & 1.008 & 1.028 \\
\hline Ateless & $27 \cdot 7$ & 0.08 & 0.128 & 0.863 & 0.754 & 31.3 & 0.01 & 0.083 & 0.876 & 0.825 \\
\hline Ranout & 23 & 0.632 & 0.136 & 1.348 & 1.162 & 19.5 & 1.271 & 0.095 & 1.049 & 0.92 \\
\hline Skipped & $19 \cdot 6$ & 1.076 & 0.144 & 0.761 & 0.6 & 22.9 & 0.873 & 0.09 & 0.84 & 0.697 \\
\hline Hungry & 17.9 & 1.325 & 0.149 & 0.775 & 0.567 & 21.3 & 1.055 & 0.092 & 0.868 & 0.65 \\
\hline Whlday & 14.8 & 1.829 & 0.162 & 0.881 & 0.708 & $15 \cdot 4$ & 1.864 & 0.105 & 1.081 & 1.321 \\
\hline
\end{tabular}

sev, severity; Whlday, whole day; all means and Rasch models estimated with household-level sampling weights.

Table 2 Comparison of the severity parameters from the raw summative score of the Latin American and Caribbean Food Security Scale (ELCSA) scale between the Mexican National Health and Nutrition Survey (ENSANUT) 2018 and the three ENCOVID-19 surveys from April, May and June 2020

\begin{tabular}{|c|c|c|c|c|c|c|c|c|}
\hline \multirow[b]{2}{*}{ Score } & \multicolumn{2}{|c|}{ ENSANUT 2018} & \multicolumn{2}{|c|}{ ENCOVID-19 April } & \multicolumn{2}{|c|}{ ENCOVID-19 May } & \multicolumn{2}{|c|}{ ENCOVID-19 June } \\
\hline & Severity & SE & Severity & SE & Severity & SE & Severity & SE \\
\hline 0 & $-4 \cdot 106$ & 1.601 & -3.589 & 1.577 & $-3 \cdot 363$ & 1.601 & $-3 \cdot 187$ & 1.552 \\
\hline 1 & -3.076 & 1.252 & -2.654 & $1 \cdot 218$ & $-2 \cdot 386$ & 1.239 & $-2 \cdot 273$ & $1 \cdot 180$ \\
\hline 2 & -1.779 & 1.058 & -1.500 & 0.973 & $-1 \cdot 213$ & 0.966 & $-1 \cdot 209$ & 0.941 \\
\hline 3 & -0.875 & 1.001 & -0.656 & 0.877 & -0.399 & 0.850 & -0.429 & 0.848 \\
\hline 4 & 0.178 & 0.942 & 0.080 & 0.842 & 0.275 & 0.809 & 0.254 & 0.814 \\
\hline 5 & 1.026 & 0.907 & 0.788 & 0.846 & 0.933 & 0.817 & 0.936 & 0.823 \\
\hline 6 & 1.815 & 0.935 & 1.544 & 0.908 & 1.648 & 0.887 & 1.631 & 0.888 \\
\hline 7 & $2 \cdot 889$ & 1.144 & 2.539 & $1 \cdot 132$ & $2 \cdot 613$ & $1 \cdot 120$ & $2 \cdot 624$ & $1 \cdot 123$ \\
\hline 8 & 3.736 & 1.601 & 3.368 & 1.577 & 3.429 & 1.601 & 3.437 & 1.552 \\
\hline
\end{tabular}

Rasch models estimated with household-level sampling weights.

a small deviation from the range, it had the highest infit value in the ENSANUT survey (1.24) and the 'misfit' was not systematic. No item had systematic deviations in the outfit values (Table 1 ).

The severity parameters of the raw summative score were equivalent between surveys (Table 2). These results indicate that the summative score of ELCSA from ENCOVID-19 was able to measure equally well the three levels of food insecurity when compared with ENSANUT 2018. Overall model fit was excellent in the ENCOVID-19 surveys. Flat reliability had a value of 0.78 in the ENSANUT survey and was very similar in ENCOVID-19, April (0.74), May (0.73) and June (0.73). The assumption of conditional independence held for most pairs of items. The internal validity in ENCOVID-19 in households with and without children in May and June also confirmed its adequate psychometric performance (see online supplementary material, Supplemental Materials S.2).

Concurrent validity of food insecurity was established by its association with SES and anxiety. The Spearman correlation between the raw score of food insecurity and SES was negative and statistically significant $(-0 \cdot 4$; CI: $-0 \cdot 37-$ 0.43). Figure 1 shows a clear dose-response gradient between SES and food insecurity severity. Even though mild food insecurity was present at every SES level, moderate and severe food insecurity increased as SES dropped. At the lowest SES level, moderate and severe food insecurity reached its highest prevalence, at $28.9 \%$ and $20.9 \%$, 
Food insecurity measurement during COVID-19 pandemic

Food insecurity prevalence by socio-economic status

Socio-economic status is ordered from highest $(A / B)$ to lowest $(E)$

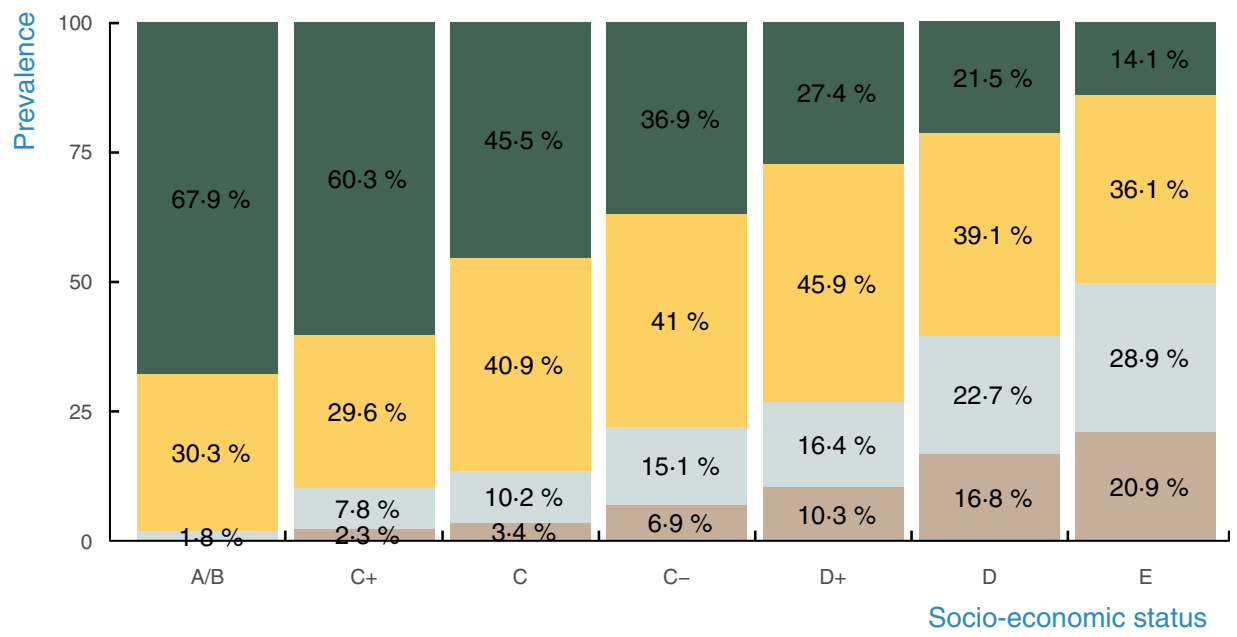

Fig. 1 (colour online) Food insecurity prevalence by socioeconomic status. The graph illustrates the inverse relationship between socio-economic status and food security. Households in the lowest SES level have the highest prevalence of moderate and severe food insecurity $(28.9 \%$ and $20.9 \%$, respectively). Conversely, households in the highest SES level have the lowest prevalence of moderate and severe food insecurity $(1.8 \%$ and $0 \%$, respectively).. , Food security; $₫$, mild food insecurity; $\ldots$, moderate food insecurity; $\sqsubset$, severe food insecurity

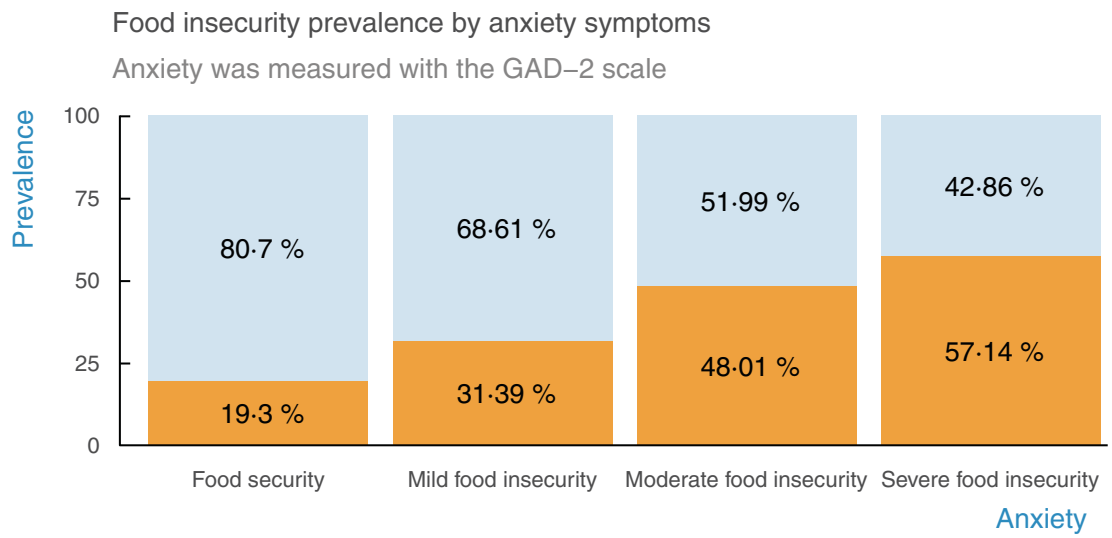

Fig. 2 (colour online) Food insecurity prevalence by anxiety symptoms. The graph illustrates the positive relationship between socioeconomic status and anxiety. Persons living in food secure households report fewer anxiety symptoms than persons living in food insecure households. , No symptoms; $\ldots$, symptoms

respectively. Notably, middle-SES households reported a prevalence of moderate and severe food insecurity from $10 \%$ in $\mathrm{C}+$ to $26 \%$ in $\mathrm{D}+$.

Anxiety was also associated with food insecurity in the expected direction. Individuals without anxiety symptoms reported a mean total food insecurity score of 1.68 , and this score was substantially higher among individuals with anxiety symptoms (3.11). Figure 2 shows the dose-response gradient between food insecurity and anxiety. While $19.3 \%$ of persons living in food secure households reported symptoms of anxiety, this was the case for $57 \cdot 1 \%$ among those living in households with severe food insecurity.

Prevalence estimates indicated that the prevalence of food security has been decreasing as the COVID-19 pandemic advances in Mexico (Table 3). According to ENSANUT 2018, $44.7 \%$ of households were food secure, but then it significantly dropped to $38.8 \%$ in April and then to $33.2 \%$ in May and 30.6\% in June 2020 (Fig. 3). Mild food insecurity reached its highest level in May (41.7\%) and moderate food insecurity in June 2020 (18.65\%). Severe food insecurity in June was not statistically different from the 2018 prevalence, very likely as a result of low statistical power; however, the secular trend since the outbreak of the pandemic suggests that severe food insecurity may also be worsening on a monthly basis. This relationship will continue to be monitored as more rounds of ENCOVID-19 data accumulate.

The stratified analysis showed that food insecurity was higher in households with than without children (Fig. 4). 
Table 3 Prevalence comparisons between the Mexican National Health and Nutrition Survey (ENSANUT) 2018 and the three ENCOVID-19 surveys from April, May and June 2020

\begin{tabular}{|c|c|c|c|c|c|c|c|c|c|c|c|c|}
\hline \multirow{4}{*}{$\begin{array}{l}\text { Food security } \\
\text { Mild FI }\end{array}$} & \multicolumn{3}{|c|}{ ENSANUT 2018} & \multicolumn{3}{|c|}{ ENCOVID-19 April } & \multicolumn{3}{|c|}{ ENCOVID-19 May } & \multicolumn{3}{|c|}{ ENCOVID-19 June } \\
\hline & \multirow{2}{*}{$\frac{\text { Prop }}{44.75}$} & \multicolumn{2}{|c|}{$\mathrm{Cl}$} & \multirow{2}{*}{$\begin{array}{l}\text { Prop } \\
38.88\end{array}$} & \multicolumn{2}{|c|}{$\mathrm{Cl}$} & \multirow{2}{*}{$\frac{\text { Prop }}{33.19}$} & \multicolumn{2}{|c|}{$\mathrm{Cl}$} & \multirow{2}{*}{$\begin{array}{l}\text { Prop } \\
30.6\end{array}$} & \multicolumn{2}{|c|}{$\mathrm{Cl}$} \\
\hline & & 43.93 & $45 \cdot 57$ & & 35.59 & $42 \cdot 18$ & & 29.64 & $36 \cdot 74$ & & 28.02 & $33 \cdot 18$ \\
\hline & 31.09 & 30.43 & $31 \cdot 75$ & 33.6 & 30.33 & 36.87 & 41.73 & 37.73 & $45 \cdot 72$ & 39.22 & 36.41 & 42.03 \\
\hline Moderate FI & 14.9 & 14.36 & 15.43 & $17 \cdot 18$ & 14.53 & $19 \cdot 82$ & 13.31 & $10 \cdot 33$ & $16 \cdot 29$ & 18.65 & $16 \cdot 42$ & $20 \cdot 89$ \\
\hline Severe FI & $9 \cdot 26$ & 8.84 & 9.68 & $10 \cdot 33$ & $8 \cdot 2$ & $12 \cdot 45$ & 11.75 & 8.84 & 14.66 & 11.51 & 9.57 & 13.45 \\
\hline
\end{tabular}

Prop, proportion; all proportions were estimated with household-level sampling weights. FI, food insecurity.

Comparison of the monthly prevalence of food insecurity

The four surveys use the ELCSA scale (8 items)

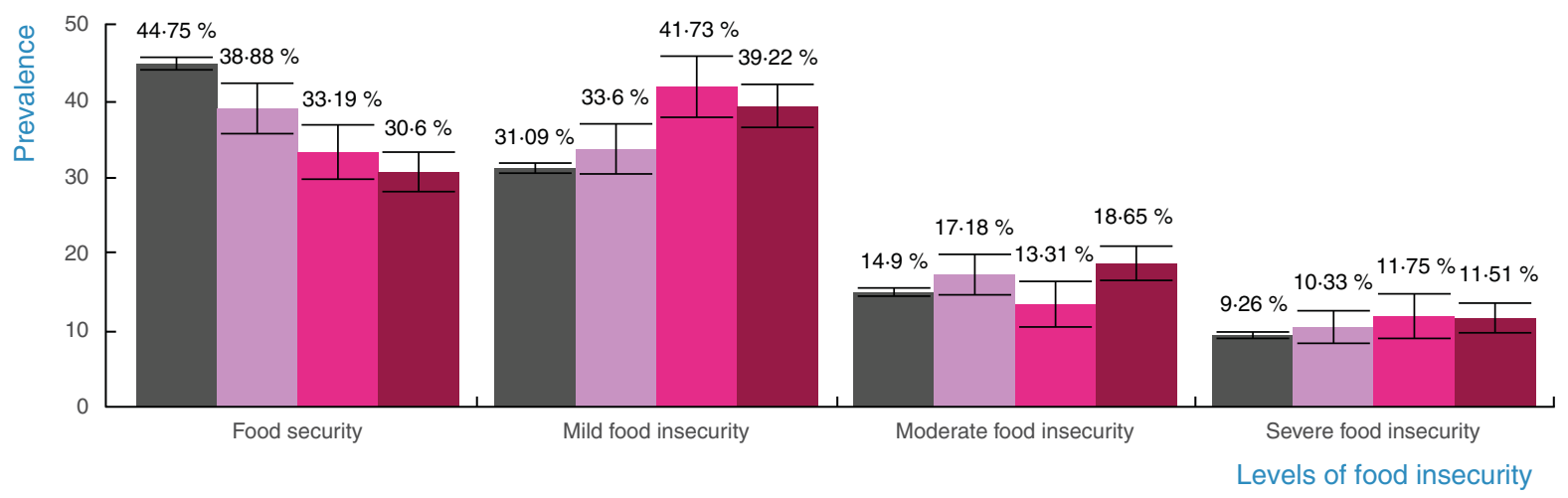

Fig. 3 (colour online) Monthly comparison of the prevalence of food insecurity. In contrast with ENSANUT from the year 2018, food security is decreasing during the COVID-19 pandemic. Mild food insecurity reached its highest level in May, and moderate food inse-

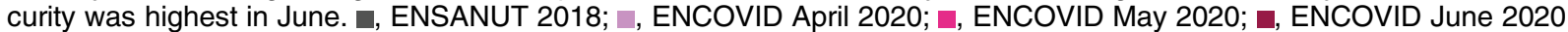

\section{Comparison of food insecurity prevalence by type of household}

The three surveys use the ELCSA scale (8 items)

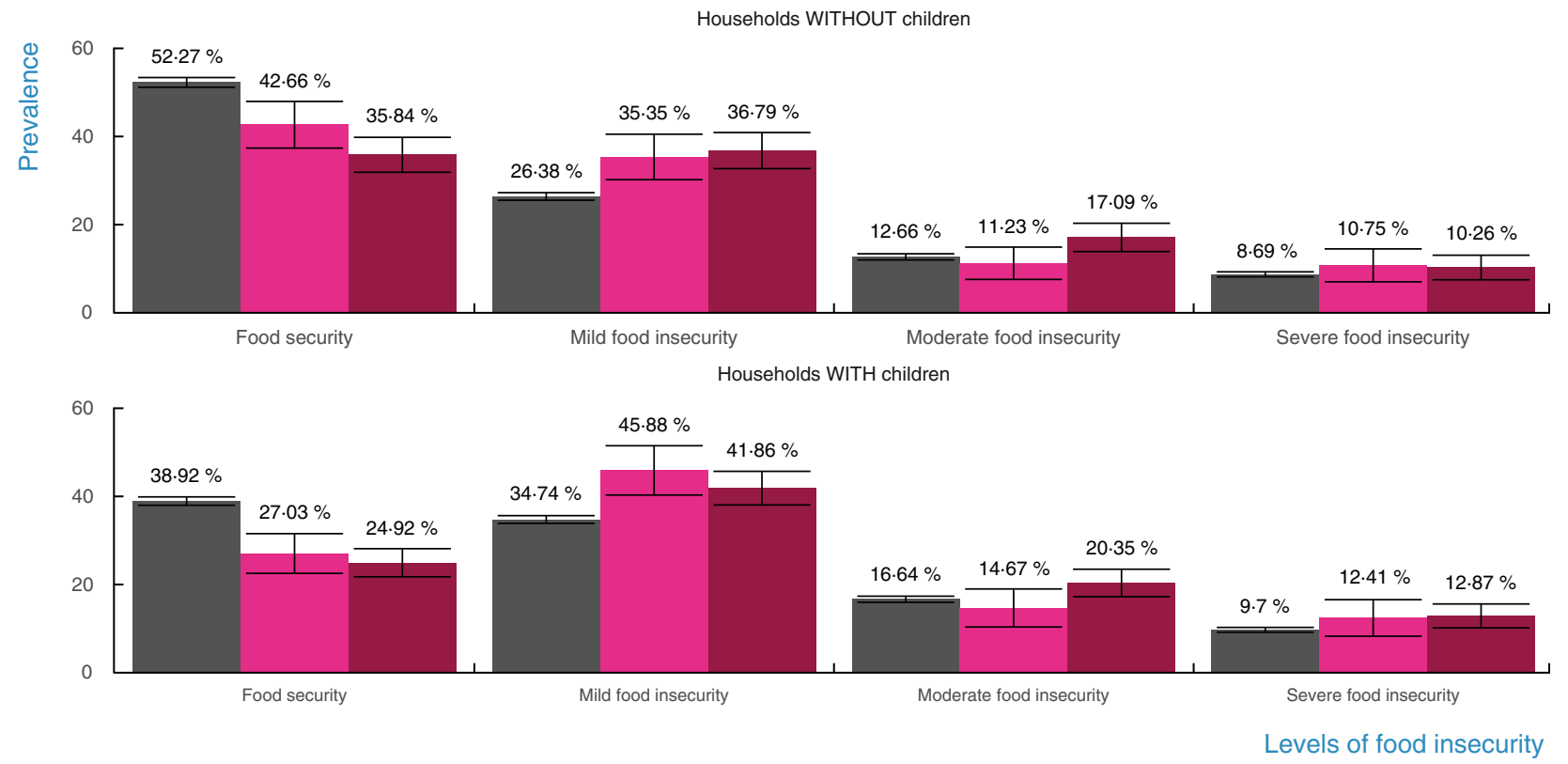

Fig. 4 (colour online) Comparison of the prevalence of food insecurity by type of household. Households with children have lower levels of food security than households without children. Households with children had the highest prevalence of mild food insecurity in May and of moderate food insecurity in June 2020. n, ENSANUT 2018; $n$, ENCOVID May 2020; $\sqsubset$, ENCOVID June 2020 
Food security in households with children decreased from $38.9 \%$ in 2008 to $27 \%$ in May and to $24.9 \%$ in June. The highest prevalence of mild food insecurity was during May $(45.8 \%)$ and for moderate food insecurity during June (20.3\%). Severe food insecurity seems to be increasing as well but confidence intervals overlapped with those of ENSANUT 2018 (see online supplementary material, Supplementary Material S.2).

\section{Discussion}

Our findings strongly suggest that the COVID-19 pandemic is increasing food insecurity in Mexico on a monthly basis during the mandated lockdown. These results are consistent with previous studies that demonstrate how in vulnerable households food security declines during socio-economic shocks ${ }^{(4,5)}$ and that as the pandemic advances food security can worsen even further ${ }^{(7,8)}$. Moreover, lockdowns associated with the pandemic might keep disrupting the food supply chain and food consumption patterns. It is especially worrisome that these disruptions might increase all forms of malnutrition during the COVID-19 pandemic, including an additional risk of obesity, due to the consumption of ultra-processed foods and increased sedentarism ${ }^{(3)}$. It is thus necessary to monitor the indirect health consequences of the COVID-19 pandemic

The adapted version of the ELCSA scale used in the ENCOVID-19 proved to be reliable and valid. Rasch models showed that the high reliability of the telephone version of the scale was comparable with the face-to-face application in ENSANUT 2018. Notably, the scale's internal consistency was strong on three independent monthly samples, which indicates that the scale was equally reliable and - combined with the Rasch analyses - showed that it can be used with a high degree of confidence to track changes in food insecurity prevalence over time. A limitation of ENCOVID-19, however, was the insufficient inclusion of persons living in rural and isolated localities due to lower mobile phone coverage. Since these communities have higher extreme poverty levels than urban enclaves in Mexico $^{(37)}$, lower coverage of these areas may have led to an underestimation of food insecurity. In spite of these limitations, thanks to ENCOVID-19, Mexico has been able to rapidly and efficiently monitor changes in food security in the general population and in diverse vulnerable locations. The positive results on the validity and reliability of the telephonic ELCSA for tracking food insecurity, together with the strong media coverage and endorsement from government officials of ENCOVID-19 findings, indicate that the main goal of this project is being met. We are now in the process of understanding if and how local and state governments, universities and international and civil society organisations are using the findings from ENCOVID-19 to design strategies and policies to protect the food security and well-being of families during the pandemic and its aftermath and on tracking their impacts on household food security.

Timely and high-quality food insecurity surveillance systems can help governments respond to the major food security challenge posed by the COVID-19 pandemic. Telephone surveys are a feasible and cost-effective strategy to measure food insecurity with experience-based scales such as ELCSA. These results can inform similar strategies in countries using the Food Insecurity Experience Scale, but they might be especially useful for countries in Latin America and the Caribbean that regularly measure food insecurity with the ELCSA scale. ENCOVID-19 is an efficient strategy to regularly monitor changes in several indicators, including food insecurity, and thus can serve as a highquality instrument that can be frequently applied to inform decision-makers and assess the performance of social protection programmes during public health emergencies and other pressing circumstances ${ }^{(38)}$.

The validity of ELCSA was also examined in its association with other variables. The selected measure of SES is a reliable assets-based scale suitable for implementation in short telephone surveys. It has previously been proved in face-to-face interviews - to be highly associated with income deciles in all states of Mexico and across localities with different population sizes ${ }^{(31)}$. However, a limitation is that this SES scale is unable to capture changes in economic circumstances, and it only reflects pre-pandemic SES. Nonetheless, households with low SES reported a considerably higher prevalence of food insecurity than those with high SES. Remarkably, food insecurity was reported in $10-26 \%$ of households in the middle of the SES scale households that may have become newly food insecure as a result of the pandemic. This means that the pandemic is negatively affecting food security in households along the SES continuum, albeit more severely among those with lower SES.

Food insecurity was also associated with anxiety. The pervasive link between food insecurity and stress helped to anticipate these results ${ }^{(15,39)}$, but the pandemic is intensifying it. During the lockdown, individuals living under conditions of moderate and severe food insecurity had more than double the anxiety levels than food secure households. These estimates were similar to what was found in a sample of US households, where anxiety was 2.09 more likely in the presence of food insecurity ${ }^{(16)}$. These results confirm the expected psycho-emotional toll and the complex syndemic interplay of mental health and the experience of food insecurity during the pandemic. As a case in point, it is possible that the increase in food insecurity in households with young children may be leading to more family chaos and poor interpersonal relations $^{(40)}$. Likewise, the stress levels in households with food insecurity may have increased the odds of suffering emotional and physical intimate partner violence ${ }^{(41)}$. It is important to keep monitoring the interaction of the two indicators because these consequences can deepen with 
the additional stress of the economic and health crisis. Examining these associations over time can indeed shed light on the syndemic effects of food insecurity and mental health on household dynamics during the pandemic ${ }^{(3)}$ and may help understand ways of intervining to address the reinforcing association between anxiety and food insecurity.

Food insecurity is more prevalent in households with children. These households require focalised social protection actions. The definition of children in ENCOVID-19 is not as granular as would have been desirable, as clusters of infants, children and adolescents, which require different policy strategies. Prior studies have already highlighted the vulnerability of young children and their families during the COVID-19 pandemic ${ }^{(3)}$. The findings of the worsening trend of food insecurity stress the urgent need for policy actions. It is important to consider providing and evaluating food assistance and cash transfers, at least to the most vulnerable households. For instance, prior studies have found that a cash transfer equivalent to one minimum wage in Mexico (\$176 USD a month) and a waiver of payment of basic services (i.e. electricity, water, etc.) to households with informal jobs and with children under 5 years of age may help protect their food security, and it would require using $<0.06 \%$ of Mexico's GDP ${ }^{(42)}$. Moreover, it is important to establish or expand food assistance programmes including cash transfers for food, food banks and school meals programmes directed to families with children, adolescents, pregnant and lactating women ${ }^{(3)}$. Beyond specific programmes, tackling these convergent syndemic-like crises will require multi-level and evidence-based policies based on a complex adaptive systems framework ${ }^{(2)}$. Even if the COVID-19 recedes, its socio-economic and health effects are expected to last for a long time.

\section{Conclusion}

Household food insecurity is worsening as the COVID-19 pandemic advances in Mexico. The causal web between the socio-economic shocks, food insecurity and adverse health and mental health outcomes needs to be addressed as a complex syndemic with comprehensive and multilevel policy actions. The results of the study show that the ELCSA scale is a valid and reliable instrument to track food insecurity in the general population and among key vulnerable groups, such as those with low and middle SES. Governments should not attempt to navigate the COVID-19 pandemic blindfolded. High-quality and costeffective strategies to monitor food insecurity are available and should be implemented widely.

\section{Acknowledgements}

Acknowledgements: The authors thank Victor Hugo Pérez Hernández, researcher at EQUIDE, for his leadership in collecting the ENCOVID-19 data. The authors acknowledge Jesús David Aban-Tamayo for his help with the
ENSANUT 2018 data management. Financial support: The ENCOVID-19 has been funded by several institutions. The April wave was financed by Universidad Iberoamericana Mexico City. The May and June waves were financed by UNICEF and the Organización de Estados Iberoamericanos para la Educación, la Ciencia y la Cultura (OEI) Mexico. Universidad Iberoamericana, UNICEF and OEI had no role in the design, analysis or writing of this article. Conflict of interest: None. Authorship: P.G.R. design, analysis, data interpretation and drafting of the manuscript. M.V.C. design, data interpretation and drafting of the manuscript. G.T.B. design and data acquisition of the ENCOVID-19 and critical revision of intellectual content. R.P.E. conception of the article, data interpretation and critical revision of intellectual content. Ethics of human subject participation: The current study was conducted according to the guidelines laid down in the Declaration of Helsinki, and all procedures involving research study participants were approved by the Universidad Iberoamericana Research Ethics Committee (registry: CONBIOÉTICA-09-CEI-008-2016060). Verbal informed consent was obtained from all subjects/patients. Verbal consent was witnessed and formally recorded.

\section{Supplementary material}

For supplementary material accompanying this paper visit https://doi.org/10.1017/S1368980020004000

\section{References}

1. FAO, IFAD, UNICEF et al. (2020) The State of Food Security and Nutrition in the World 2020. Transforming food systems for affordable bealthy diets. Rome: FAO.

2. Vilar-Compte M, Gaitan-Rossi P, Flores D et al. (2019) How do context variables affect food insecurity in Mexico? Implications for policy and governance. Public Health Nutr 23(13), 1-8.

3. Pérez-Escamilla R, Cunningham K \& Moran VH (2020) COVID-19, food and nutrition insecurity and the wellbeing of children, pregnant and lactating women: A complex syndemic. Matern Child Nutr 16, e13036.

4. Gundersen C, Kreider B \& Pepper J (2011) The economics of food insecurity in the United States. Appl Econ Perspect Policy 33, 281-303.

5. Vilar-Compte M, Sandoval-Olascoaga S, Bernal-Stuart A et al. (2015) The impact of the 2008 financial crisis on food security and food expenditures in Mexico: a disproportionate effect on the vulnerable. Public Health Nutr 18, 2934-2942.

6. Raifman J, Bor J \& Venkataramani A (2020) Unemployment insurance and food insecurity among people who lost employment in the wake of COVID-19. MedRxiv. Published online: 30 July 2020. doi: 10.1101/2020.07.28. 20163618.

7. Enriquez D \& Goldstein A (2020) Covid-19's socio-economic impact on low-income benefit recipients: early evidence from tracking surveys. SocArXiv. Published online: 16 June 2020. doi: 10.31235/osf.io/hpqd5.

8. Manfrinato CV, Marino A, Conde VF et al. (2020) High prevalence of food insecurity, the adverse impact of COVID-19 in 
Brazilian favela. MedRxiv. Published online: 04 August 2020. doi: 10.1101/2020.07.31.20166157.

9. Niles MT, Bertmann F, Belarmino EH et al. (2020) The early food insecurity impacts of COVID-19. MedRxiv. Published online: 13 May 2020. doi: 10.1101/2020.05.09.20096412.

10. Hamadani JD, Hasan MI, Baldi AJ et al. (2020) Immediate impact of stay-at-home orders to control COVID-19 transmission on socioeconomic conditions, food insecurity, mental health, and intimate partner violence in Bangladeshi women and their families: an interrupted time series. The Lancet Global Health. Published online: 25 August 2020. doi: 10. 1016/S2214-109X(20)30366-1.

11. FAO I, The World Bank \& WFP (2020) Joint Statement on COVID-19 Impacts on Food Security and Nutrition. Rome, Washington DC. http://www.fao.org/news/story/en/item/ 1272058/icode/ (accessed May 2020).

12. Dou Z, Stefanovski D, Galligan D et al. (2020) The COVID-19 pandemic impacting household food dynamics: a crossnational comparison of China and the U.S. SocArXiv. Published online: 23 May 2020. doi: 10.31235/osf.io/64jwy.

13. FAO (2020) Urban Food Systems and COVID-19: The Role of Cities and Local Governments in Responding to the Emergency. Rome: Food and Agriculture Organization of the United Nations.

14. Jones AD (2017) Food insecurity and mental health status: a global analysis of 149 countries. Am J Prev Med 53, 264-273.

15. Pourmotabbed A, Moradi S, Babaei A et al. (2020) Food insecurity and mental health: a systematic review and metaanalysis. Public Health Nutr 23, 1778-1790.

16. Lauren BN, Silver ER, Faye AS et al. (2020) Predictors of household food insecurity in the United States during the COVID-19 pandemic. MedRxiv. Published online: 12 June 2020. doi: $10.1101 / 2020.06 .10 .20122275$.

17. UNICEF, WHO \& WFP et al. (2020) Joint Statement on Infant and Young Child Feeding in the Context COVID-19 Pandemic. https://www.unicef.org/srilanka/press-releases/joint-statementinfant-and-young-child-feeding-context-covid-19-pandemic (accessed 16 de junio de 2020)

18. Oliveira KHD, Almeida GM, Gubert MB et al. (2020) Household food insecurity and early childhood development: systematic review and meta-analysis. Matern Child Nutr 16, e12967.

19. Pedroso J, Buccini G, Venancio SI et al. (2020) Maternal mental health modifies the association of food insecurity and early child development. Matern Child Nutr 16, e12997.

20. Kola L (2020) Global mental health and COVID-19. Lancet Psychiatr 7, 655-657.

21. Singer M, Bulled N, Ostrach B et al. (2017) Syndemics and the biosocial conception of health. Lancet 389, 941-950.

22. FAO (2012) Escala Latinoamericana y Caribeña de Seguridad Alimentaria (ELCSA). Manual de uso y aplicación (Latin American and Caribbean Food Security Scale (ELCSA): User Manual and Application). Chile: FAO.

23. FAO (2016) Methods for Estimating Comparable Rates of Food Insecurity Experienced by Adults throughout the World. Rome: FAO.

24. Cafiero C (2020) Using the Food Insecurity Experience Scale (FIES) to Monitor the Impact of COVID-19. Voices of the Hungry. Rome: FAO.

25. Nord M \& Hopwood H (2007) Does interview mode matter for food security measurement? Telephone versus in-person interviews in the Current Population Survey Food Security Supplement. Public Health Nutr 10, 1474-1480.

26. Teruel Belismelis G, Pérez Hernández VH, Gaitán-Rossi P et al. (2020) Encuesta Nacional sobre los Efectos del COVID-19 en el Bienestar de los Hogares Mexicanos (ENCOVID-19-ABRIL) (National survey on the effects of COVID-19 on the wellbeing of Mexican households (ENCOVID-19- APRIL)), 1 ed. [EQUIDE, editor]. Mexico. doi: 10.5281/zenodo.3950528 (accessed July 2020).
27. IFT (2020) Plan Nacional de Numeración (National Dialing Plan). https://sns.ift.org.mx:8081/sns-frontend/planesnumeracion/descarga-publica.xhtml (accessed July 2020).

28. INEGI (2019) Encuesta Nacional sobre Disponibilidad y Uso de Tecnologías de la Información en los Hogares (ENDUTIH) (National Survey of Households' Availability and Use of Information Technology). https://www.inegi.org.mx/ programas/dutih/2019/ (accessed June 2020).

29. Pérez-Escamilla R, Melgar-Quiñonez H, Nord M et al. (2007) Escala Latinoamericana y Caribeña de Seguridad Alimentaria (ELCSA). Memorias de la $1^{\text {a }}$ Conferencia en América Latina y el Caribe sobre la medición de la seguridad alimentaria en el hogar (Latin American and Caribbean Food Security Scale (ELCSA). Proceedings of the 1st Latin American and Caribbean Conference on the household food security measurement). Perspectivas en Nutrición Humana. Published online: 06 June 2020. doi: 10.17533/udea.penh.

30. Villagómez-Ornelas P, Hernández-López P, CarrascoEnríquez B et al. (2013) Validez estadística de la Escala Mexicana de Seguridad Alimentaria y la Escala Latinoamericana y Caribeña de Seguridad Alimentaria (Statistical validity of the Mexican Food Security Scale and the Latin American and Caribbean Food Security Scale). Salud Pública México 56, s5-s11.

31. AMAI (2018) Nivel Socioeconómico AMAI. Nota Metodológica (Socioeconomic Level AMAI). Mexico: Asociacion Mexicana de Agencias de Inteligencia Mercado y Opinion.

32. Garcia-Campayo J, Zamorano E, Ruiz MA et al. (2012) The assessment of generalized anxiety disorder: psychometric validation of the Spanish version of the self-administered GAD-2 scale in daily medical practice. Health Qual Life Outcomes 10, 114.

33. Revelle W \& Zinbarg RE (2008) Coefficients Alpha, Beta, Omega, and the glb: comments on Sijtsma. Psychometrika 74, 145-154.

34. Melgar-Quiñonez H, Zubieta AC, Valdez E et al. (2005) Validación de un instrumento para vigilar la inseguridad alimentaria en la Sierra de Manantlán, Jalisco (Validation of an instrument to monitor food insecurity in Sierra de Manantlán, Jalisco). Salud Pública de México 47, 413-422.

35. Nord M (2014) Introduction to Item Response Theory Applied to Food Security Measurement: Basic Concepts, Parameters, and Statistics. Rome: FAO.

36. Viviani S (2016) Manual for the Implementation of the FAO Voices of the Hungry Methods to Estimate Food Insecurity: RM.weights Package in R. Rome: FAO.

37. CONEVAL (2014) Pobreza urbana y de las zonas metropolitanas en Mexico (Urban and Metropolitan Poverty in Mexico). 1-80. https://www.coneval.org.mx/Informes/ Pobreza/Pobreza\%20urbana/Pobreza_urbana_y_de_las_zonas_ metropolitanas_en_Mexico.pdf (accessed June 2020).

38. Blom AG, Cornesse C, Friedel S et al. (2020) High frequency and high quality survey data collection. The Mannheim Corona Study. Surv Res Methods 14, 171-178.

39. Perez-Escamilla F \& de Toledo Vianna RP (2012) Food insecurity and the behavioral and intellectual development of children: a review of the evidence. J Appl Res Child: Inform Policy Child Risk 3, 9.

40. Rosemond TN, Blake CE, Shapiro CJ et al. (2019) Disrupted relationships, chaos, and altered family meals in foodinsecure households: experiences of caregivers and children. J Acad Nutr Diet 119, 1644-1652.

41. Diamond-Smith N, Conroy AA, Tsai AC et al. (2019) Food insecurity and intimate partner violence among married women in Nepal. J Glob Health 9, 010412.

42. Vilar-Compte M, Perez V, Teruel G et al. (2020) Costing of actions to safeguard vulnerable Mexican households with young children from the consequences of COVID-19 social distancing measures. Int J Equity Health 19, 70. 